\title{
Autonomous vehicle interactions in the urban street environment: a research agenda
}

\author{
John Parkin BSC (Eng) (Hons), ACGI, MSC, PhD, PGCE, CEng, FICE, \\ FCIHT, FCILT, FHEA \\ Professor, University of the West of England, Bristol, UK \\ (corresponding author: john.parkin@uwe.ac.uk) \\ Benjamin Clark BSC (Hons), MA, MSc, PhD \\ Senior Lecturer, University of the West of England, Bristol, UK \\ William Clayton BA, MA, PhD \\ Senior Lecturer, University of the West of England, Bristol, UK
}

\author{
Miriam Ricci MSc, PhD \\ Senior Research Fellow, University of the West of England, Bristol, UK \\ Graham Parkhurst BA, MSC, DPhil \\ Professor, University of the West of England, Bristol, UK
}

The Venturer project is trialling an autonomous vehicle (AV) in the context of use on urban roads. This paper summarises a literature review undertaken to assist in developing a research agenda for the trialling. The first contribution of the paper is a framework of four use scenarios for AVs as follows: (1) fully segregated AV network, (2) motorway or expressway network, (3) typical urban network, (4) shared space. The paper then focuses on a review of the social interactions in the street environment and discusses issues concerning human behaviour in relation to autonomy. The second contribution of the paper is a set of research questions for AV trialling in relation to other road users, including, pedestrians and cyclists, which have emerged from the literature review.

\section{Introduction}

The direction of travel in technology development in the automotive industry is towards increasing levels of autonomy. This may result in a progressive transfer from the current predominance of human-controlled motorised vehicles on the public highway, towards use of vehicles with increasing degrees of autonomy. It is unclear, however, how autonomous vehicles $(\mathrm{AVs})$ will integrate into the full range of existing types of public rights of way, and, more importantly, how they will integrate with the full range of road users, including pedestrians, cyclists and drivers and passengers of humandriven motor vehicles. To this end, Innovate UK is funding a series of projects to trial AV technology. One of these projects, the Venturer project (Venturer-Cars, n.d.) is undertaking trials using the Wildcat vehicle, see Figure 1. This paper is based on a review of literature (Parkin et al., 2016) undertaken to develop research questions to help inform the nature of the trials.

SAE International (2014: p. 2) summarises generally accepted levels of autonomy as follows

- Level 0 No automation: the full-time performance by the human driver of all aspects of the dynamic driving task, even when enhanced by warning or intervention systems.

- Level 1 driver assistance: the driving mode-specific execution by a driver assistance system of either steering or acceleration/deceleration using information about the driving environment and with the expectation that the human driver performs all remaining aspects of the dynamic driving task.

- Level 2 partial automation: the driving mode-specific execution by one or more driver assistance systems of both steering and acceleration/deceleration using information about the driving environment and with the expectation that the human driver performs all remaining aspects of the dynamic driving task.

- Level 3 conditional automation: the driving mode-specific performance by an automated driving system of all aspects of the dynamic driving task with the expectation that the human driver will respond appropriately to a request to intervene.

- Level 4 high automation: the driving mode-specific performance by an automated driving system of all aspects of the dynamic driving task, even if a human driver does not respond appropriately to a request to intervene.

- Level 5 full automation: the full-time performance by an automated driving system of all aspects of the dynamic driving task under all roadway and environmental conditions that can be managed by a human driver

AV technology has reached level 3 in the above hierarchy under test conditions. The information technology company Google is operating level 3 vehicles on public roads with handover between the automated system and a trained 'safety driver'. Simonite (2013) reports Google's self-drive project head as saying that hundreds of thousands of miles of travel shows that their AV accelerated and braked significantly less 
Autonomous vehicle interactions in

the urban street environment:

a research agenda

Parkin, Clark, Clayton, Ricci and Parkhurst

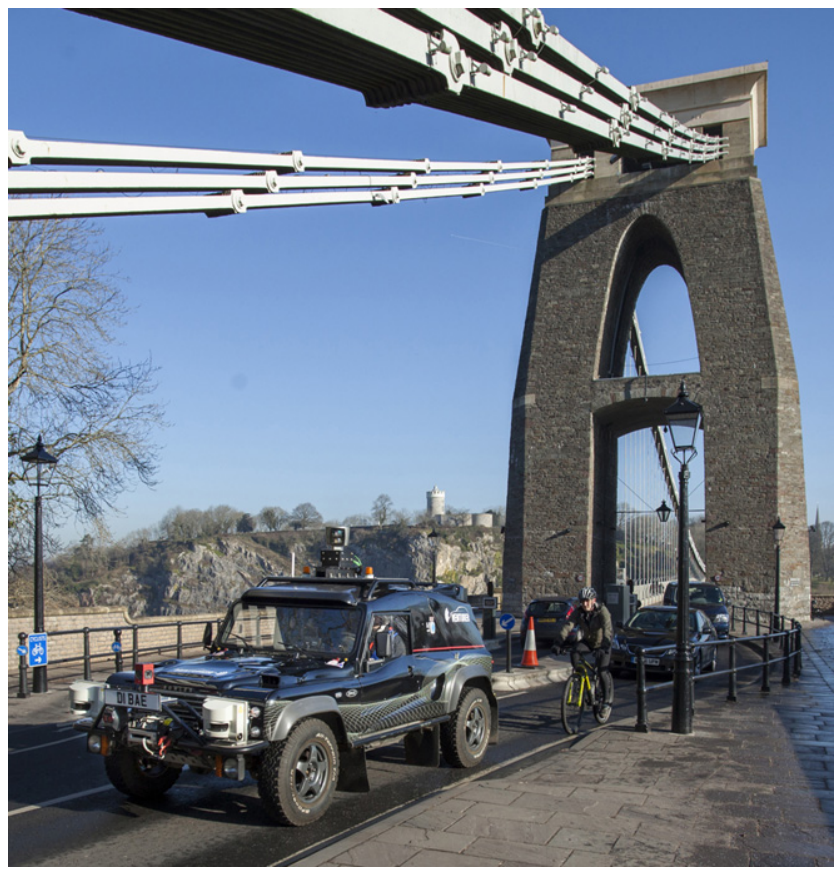

Figure 1. The Wildcat vehicle (photo credit: Chris Bahn)

sharply than when humans were driving, and that the Google car was much better than human drivers at maintaining a safe distance from the vehicle ahead.

Volvo (VCG, 2014) is using technology they call 'Autopilot', which can follow lanes, adapt speed and perform merges autonomously. Further developments (VCG, 2015) suggest they are ready for public trials, and this readiness is based on complete systems that will 'fail safe'. Audi (2015) has completed a 550 mile 'piloted' drive from Silicon Valley to Las Vegas. BMW is to introduce $\mathrm{AVs}$ already tested in Germany into Chinese cities in partnership with the search engine Baidu (Forbes, 2014).

More controversially, level 3 capabilities are now being provided commercially, with caveats to users that suggest the systems should only be used in driver assistance mode, and not in autonomous mode. Based on two deaths to date in Tesla vehicles, these caveats are of debatable effectiveness. Tesla (2015) has released an initial version of its technology (also called 'Autopilot') on the Model S vehicle. The Tesla Autopilot feature involves four elements: Autosteer, Auto Lane Change, Automatic Emergency Steering and Side Collision Warning and Auto Park. Tesla states that 'The latest software update, 7.0 allows Model $\mathrm{S}$ to use its unique combination of cameras, radar, ultrasonic sensors and data to automatically steer down the highway, change lanes, and adjust speed in response to traffic' (Tesla, 2015).
These developments suggest an urgent need to consider the implications of the increasing availability and level of assistance provided to drivers and their impacts on the full range of road users in the urban street environment. In addition, it is necessary to consider a future where vehicles might be used with full autonomy.

The focus in the Venturer project has been on an AV broadly the size and shape of a large car, and also a pod. The project will also involve testing the behaviour of the AV around a bus. The specific context for the study has been the urban highway. There are a number of interesting issues in relation to HGVs, and the focus here has been more on infrastructure to vehicle communication and platooning. Section 2 describes the very different scenarios in which $\mathrm{AVs}$ may be used. Interactions between $\mathrm{AVs}$ and other road users in the street environment are discussed in Section 3. Threads are drawn together in the form of recommendations for research based on the literature in Section 4, and the next steps for research on the Venturer project are outlined in Section 5.

\section{Use scenario classification}

There are a number of scenarios under which road-based AVs could operate. In the extreme, AVs might only operate in a system segregated from other, non-autonomously controlled, road users. Alternatively, were they to operate on an existing public road network in current types of traffic condition, then they would be subject to interactions with all types of vehicle, driver, cyclist and pedestrian. These two extremes could hardly be more different in terms of what would be expected of an AV and the ways in which it would have to interact, manage and negotiate its way through a system.

Skinner and Bidwell (2016) envision a future dominated by $\mathrm{AVs}$ and note the benefits and impacts in city centres, suburban spaces, motorways and rural areas. The set of AV use scenarios developed below further frame the discussion, and provide a defined scope for understanding the relevance of current and proposed research to AV use. These are as follows

- Use Scenario 1: Fully segregated AV network - In whatever form this may be (e.g. pods or similar vehicles). AVs are completely segregated from other road users and operate within their own system. AVs would interact only with other $\mathrm{AVs}$ and the infrastructure of the network.

- Use Scenario 2: Motorway or expressway network - This scenario is a situation in which $\mathrm{AV}$ s operate alongside human-controlled vehicles, however, only within a constrained subset of roads on the general network, that is high-volume, high-speed roads and where there may be a significant amount of instrumentation and management (e.g. Smart Motorways, Highways England (HE, 2016)). 
In this scenario, $\mathrm{AVs}$ will interact with other $\mathrm{AVs}$, human drivers and the infrastructure of the road network (grade separated junctions with merges and diverges, lanes and signage including variable speed limits), but not intended, or at least very few, non-motorised road users.

- Use Scenario 3: Typical Urban network - This complex scenario comprises the typical roads found in urban and suburban areas and includes arterial roads, distributor roads, high streets, access roads and local streets. There will be a wide range of different types of road user, as well as a need to navigate various forms of junction and other complex infrastructure and a high level of different types of regulation (e.g. speed, parking and loading). AVs will interact with other $\mathrm{AVs}$, human drivers (of a variety of vehicle types including buses, delivery vehicles, taxis and motorcycles), pedestrians and cyclists, and with the infrastructure of the road network (signalised, roundabout and priority junctions, variable numbers of lanes and bus and cycle lanes, regulatory and direction signs, parking areas, a variety of traffic regulation orders, footways and pedestrian crossings).

- Used Scenario 4: Shared space - Shared space is an urban design approach which seeks to minimise the separation between different types of users in order to enhance priority for pedestrians and cyclists, which is often absent from much of the public highway. It does this by careful design to reduce motor traffic speeds and usually entails removing features such as kerbs, road surface markings, traffic signs and traffic lights, and by introducing subtle and naturalistic forms of speed control through different surface colours and textures and roadside features. Increasing skill and knowledge about the nature of appropriately designed shared space is growing as more schemes are implemented. In this final scenario, AVs will need to navigate an environment which is less well defined and regulated than a typical urban highway network. AVs will be expected to interact with every type of user on an equal basis with no defined priority. AVs will interact with other $\mathrm{AVs}$, human drivers, pedestrians and cyclists. A trial of AVs has been taking place in Sion, Switzerland in this context (Postauto, 2016)

This paper is not concerned specifically with the use scenario where AVs operate on a fully segregated network, and these scenarios already exist within the transport sector, for example, the Heathrow Terminal 5 ULTra network of guided, electrically powered 4- to 6-seat 'Pod' vehicles (ULTraglobalPRT, 2016). These 'AV system only' considerations form only a minor part of the whole issue of introducing $\mathrm{AVs}$ into the transport network. The challenge at hand is with the introduction of AVs into the existing highway network where there are other road users who are humans and who therefore behave as humans. Section 3 discusses these issues.

\section{Social aspects of interactions in the street environment}

To understand the complexity of the task facing AVs in successfully and safely navigating the road network, it is necessary to identify and explicate that which is currently known about interactions between its various users. First, road use as a social practice is discussed, and this is followed by a discussion of one particular aspect of human behaviour in the street environment: aggressive behaviour. This is followed by a discussion of the physical manifestation of failure to resolve conflict, that is collisions, and a conclusion discussing the management of the environment from a regulatory point of view.

\subsection{The car and driving as social practice}

Wilde (1976) suggested that, despite the degree of anonymity available to road users, participation in traffic does not in fact take place in a social vacuum. Individual performance of the functions relating to road use takes place in the context of a collective of road users, characterised by social habits and social values, by certain expectations, and by methods of communication.

Thrift (2004) also notes that the system of driving or road use more generally has a significant social element and he suggests that the private car is a deeply ingrained cultural icon. He points out that the road system is hugely complex and well established, with many types of interaction. Even non-drivers are likely to encounter the road network and its traffic almost daily. AVs are therefore not only entering a functional system within which humans operate, but they are also entering a system heavily laden with different meanings for different users.

Rules, customs and bespoke modes of communication exist within this social layer of the system, which is laid on top of the functional elements of the road network. Drivers, for example, regularly wave, flash their lights, nod their head, speed up or slow down, beep their horn and use hand gestures, all to communicate different things to other road users in different contexts. The implication is that $\mathrm{AVs}$, in managing interactions with other road users, will need to have some degree of understanding of these socially constructed elements of the system. AVs therefore must first be able to recognise and respond appropriately to social cues, but most importantly, may also need to actively comply with the informal rules and communications that occur.

Two significant challenges emerge. First, human drivers and other road users may not behave in a way that is sufficiently patterned for machine intelligence to be able to predict, reliably, what actions other road users are about to perform. It remains to be seen whether this is simply a temporary problem due to the availability of sufficient computing power and machine experience. Second, humans communicate their 
intentions on the road network in subtle and tacit ways. For example, they use gestures. While machines are growing in their capacity to understand gestures, some of that understanding is not yet sufficiently robust for safety-critical applications.

Non-verbal communication is negotiated according to longrunning and often national, culturally specific expectations. For example, the UK highway code (and the equivalent in other jurisdictions) specifies a headlight flash as an alternative to the auditory warning of a horn. An Italian motorist flashing the headlights is an indication of an intention not to alter trajectory. However, in the United Kingdom, in practice, the headlight flash has an almost opposite meaning to the Highway Code definition: to indicate that priority is being yielded to another road user in a situation of uncertainty. Such variability of context-specific meanings remains one of the greatest challenges for $\mathrm{AV}$ decision systems.

\subsection{Aggressive behaviour}

Aggressive driving behaviours are relatively common, and thus it follows that an $\mathrm{AV}$ must be able to recognise, at least in terms of a behaviour pattern, and respond in an appropriate manner to instances where rational behaviour is overtaken by emotional responses by human road users. The American Automobile Association (AAA, 2009: p. 10) notes that 'surveys consistently show that people believe aggressive driving is one of the most serious traffic safety problems'. This is therefore an area of particular concern for $\mathrm{AVs}$.

Aggressive driving is engaging in dangerous or forceful manoeuvring of the vehicle but without the specific intention to harm someone else, while road rage is usually taken to mean an incident in which a driver takes actions with the specific intention of harming another road user (Schafer, 2015). Though both forms of behaviour are similar in that they place others at significant risk, the distinction is merited because of the differences in motivation, driver personality and outcomes of each behaviour (Hennessy, 2011; Miles and Johnson, 2003; Schafer, 2015) and whether they are regarded as traffic violations or criminal acts (Sanders, 2002; Schafer, 2015). This important issue is picked up again in the next section.

\subsection{Collisions and conflicts}

The majority of collisions on roads are a result of human causes, and usually a combination of more than one type of human error or violation, plus possibly other vehicle and infrastructure factors (Sabey and Taylor, 1980). The UK Department for Transport (DfT, 2015a) suggest that the top five contributory factors are as follows: driver/rider failed to look properly, $46 \%$; driver/rider failed to accurately judge other person's path or speed, $24 \%$; driver/rider careless, reckless or in a hurry, 18\%; poor turn or manoeuvre, $16 \%$; loss of control, $13 \%$. Such human factor-related concerns are promoted as a principal reason why all major governments including those in the United Kingdom, the United States and Europe are pursuing the agenda of $\mathrm{AV}$ development (DfT, 2015b: p. 4).

The propensity for unsafe human driving presents a significant challenge to $\mathrm{AVs}$ because the $\mathrm{AVs}$ themselves will be at risk of being involved in a collision or other unsafe situation, which is the result of human error, and over which they may have little control. Therefore, understanding unsafe driving practices is important so that AVs may be equipped with the necessary technology and decision systems to respond in the most appropriate way when confronted with potentially hazardous situations.

Svensson and Hydén (2006: p. 380) define a conflict as 'a situation where two or more road users approach each other in time and space to such an extent that a collision is imminent if their movements remain unchanged'. A collision may therefore be defined as an unsuccessfully resolved conflict (Risser, 1985). The challenge to understanding conflict as a form of traffic interaction is that the majority of examples go unobserved. The majority of existing knowledge about road user interactions (especially empirical knowledge) focuses on serious conflicts and collisions, while the bulk of everyday road user interactions simply occur without incident and are thus not of particular interest from a traffic safety perspective.

Conflicts, or 'near misses', may, however, be of interest from the point of view of user experience, particularly nonmotorised user experience because they may be unpleasant and hence discouraging (Aldred, 2016).

\subsection{Managing the regulatory environment}

Goldhill (2015) asks 'should driverless cars kill their own passengers to save a pedestrian?' This moral dilemma was first explored by Foot (1967) and became known as the 'Trolley Problem'. Utilitarianism suggests the correct course of action is the one that 'maximises happiness', in this case minimising the loss of life. Others would argue that AVs should not be programmed to allow it to kill people external to the vehicle, with $\mathrm{AV}$ users knowing the risks.

Providing a preliminary popular resolution to the issue, Bonnefon et al. (2015) found that $75 \%$ of a cohort of lay respondents $(n=201)$ agreed that an $\mathrm{AV}$ should swerve into a barrier (killing its sole passenger) to save ten pedestrians. In an extension of their study (Bonnefon et al., 2016), they found, however, that this conviction weakened dramatically when they themselves were the driver. This result was revealed by a significantly reduced positive response to a question about how 
happy they themselves would be to either buy a utilitarian AV, and/or to accept government regulation mandating this type of programming. These crucial questions are being explored as part of the Venturer project, and they are not further dwelt on in this paper.

Adams (2015) examines how current visions of a driverless future neglect to take full account of pedestrians and cyclists and focus on vehicle-to-vehicle interactions controlled by algorithm. In the case of interactions between $\mathrm{AVs}$ and pedestrians and cyclists, programming to behave 'deferentially' could lead to AVs spending their time 'going nowhere', suggesting that $\mathrm{AV}$ s may not be a very efficient transport mode in urban environments. AV deference was exemplified by a chance encounter between a Google AV and a cyclist (Lewis, 2015) during a test drive on a public road in Austin, Texas. Although the car had arrived first at the intersection and had right of way, it was misled by the track stand manoeuvre executed by the cyclist while he waited for the AV to go, and was unable to move from the intersection for $2 \mathrm{~min}$.

\section{Recommendations for research}

A series of research questions has been developed, answers to which would provide some clarity in relation to the introduction of $\mathrm{AVs}$ into existing urban road networks. The questions have been developed after a literature review of interactions between road users and the infrastructure (Parkin et al., 2016).

After introducing the relevant background literature, the resulting research questions (RQs) are introduced in bold type. The introduction of $\mathrm{AVs}$ is being promoted in the United Kingdom on the basis of a number of small-scale trials of the technology. This appropriately cautious approach means that initial trials will use only a single or a very small number of AVs. Many RQs, however, would need a significant proportion of the motor vehicle fleet to be autonomous. To this end, many RQs will not be answerable in early trials.

As a context for the discussion, it should be borne in mind that pedestrians and cyclists have a right to 'pass and repass' on the public highway. However, the right to use the public highway using motor vehicles is subject to possession of both a vehicle licence and driving licence. These rights are subject to regulation orders put in place to manage the road environment.

\subsection{Interactions between AVs and motor vehicles}

Gstalter and Fastenmeier (2010) investigated errors committed in driving relative to the number of opportunities for errors based on a taxonomy of tasks and definitions for correct behaviours and errors in behaviour. $R Q$ : As a result of their greater predictability, will the presence of $A V s$ introduce a degree of additional control into the vehicle mix, resulting in fewer errors by drivers?

As discussed above a number of studies have found that the rate of aggressive driving in relation to collisions is high (AAA, 2009; Asbridge et al., 2003; Dąbrowski, 2014; Joint, 1997; RoSPA, 2011). RQ: How might an AV manage a situation in which another driver is being deliberately antagonistic, and driving in a manner with the intention to harm the AV andlor its occupants? While automation such as co-operative adaptive cruise control could help create uniform headway and similar velocities throughout a platoon, hence improving reliability and reducing collisions (Hardy and Fenner, 2015), decision making in mixed traffic streams would require $\mathrm{AVs}$ to respond to aggressive behaviour. $R Q$ : What decision making behaviour may be required of an $A V$ to deal with aggressive behaviour of a human driver in a following vehicle?

Harrell and Spaulding (2001) suggest that the decision to accept a gap when making manoeuvres at junctions is related to the value of undertaking the manoeuvre relative to the potential cost of undertaking the manoeuvre and use Gray and Tallman (1984) model. Gap acceptance is understood and negotiated tacitly between drivers (i.e. a driver in the major stream who sees a vehicle in a minor stream at an intersection will have certain expectations about how that driver will behave, what gap is acceptable, etc.). All of this is based on the way drivers select and view different areas of interest (Lemonnier et al., 2015; Wickens et al., 2011). RQ: Do approaching AVs engender a different gap acceptance behaviour among other road users (including cyclists and pedestrians) at junctions and does this vary depending on how obvious it is that a vehicle is an $A V$ ?

Shared space (Hamilton-Baillie and Jones, 2005), while still contested (Moody and Melia, 2014) is an urban realm improvement that seeks to reduce vehicle speed but then allow motor and other traffic to mix with pedestrians. Barriers, highway signs and road markings are replaced with subtle surface features, such as changes in colour and texture. $R Q$ : How will AVs behave in shared space?

\subsection{Interactions between AVs and cycles}

In the context of creating appropriate environments for cycle traffic, various researchers have studied motivators and deterrents (Winters et al., 2011), and modifications to the built environment (Fraser and Lock, 2010). Others have focused more on the cyclist and Dill and McNeil (2013) found most potential cyclists in the category of being 'interested but concerned', with others focusing on issues for women (such as Garrard et al., 2012). While there are complex and multifactorial reasons why people may or may not cycle, there are 
significant groups of people who may be able to take advantage of the benefits of cycling if their perceptions of, and the realities of the hazards posed by motorised traffic can be ameliorated. RQ: Will AVs assist, in the generality, in changing the perceptions of hazard posed by motorised traffic to cycle users? $R Q$ : How does the presence of AVS with differing levels of automation affect interactions and decisions made by cyclists?

Wood et al. (2009) note that poor environmental conditions can reduce a bicycle rider's conspicuousness. $R Q$ : To what extent would $A V S$ be able to detect a cyclist in the road ahead when light and weather conditions are adverse? They also noted that roads in built-up areas were associated with more door opening collisions. RQ: Can an AV remain 'passively' safe by preventing passenger egress when it is not safe to do so? Frings et al. (2014) studied attention allocation of cyclists and behavioural intentions in the context of the approach to the end of a queue of traffic. $R Q$ : Will cyclists allocate attention differently and behave differently around AVs in queueing traffic?

Various commentators suggest changes to regulation in respect of cycles themselves (Robinson and Scoons, 2013) and traffic regulation (PJAL, 2016) with particular emphasis on the value of a 'Universal Duty to Give Way' as obtains in many northern European countries. $R Q$ : What legislative changes might be particularly appropriate or helpful in the context of managing $A V$ interactions with non-motorised road users? Various research has evaluated perceived risk of environments for cycling (Harkey et al., 1998; Parkin et al., 2007; Wardman et al., 2000). RQ: How may perceived risk be altered for cycle users by the presence of $A V S$ in the vehicle stream?

An important issue in relation to cyclist comfort is the distance of a motor vehicle overtaking a cycle. This has been well researched with many studies suggesting that cycle lane markings in typical road conditions do not significantly change passing distance and the effect on comfort and perceptions of safety is mixed (Parkin and Meyers, 2010; Shackel and Parkin, 2014; Stewart and McHale, 2014; Walker, 2007). RQ: For different speeds, what is an appropriate distance to be provided by an $A V$ when overtaking a cyclist in order to provide a minimum level of comfort for the cyclist? Linked with this, research suggests that speeds are reduced when centre-lines are removed (DfT, 2007, see Figure 2), but the impact for cyclists lacks research (Stewart and McHale, 2014). RQ: Are AVs able to overtake cyclists both with and without centre line markings with no difference in the impact on cycle users' perceptions of safety?

Road narrowings can be created by pedestrian refuges, central islands, pinch points, chicanes, build-outs and hatching and other carriageway markings. There has been increasing utilisation of such features as traffic calming measures within the United Kingdom. RQ: How will cycle users negotiate road

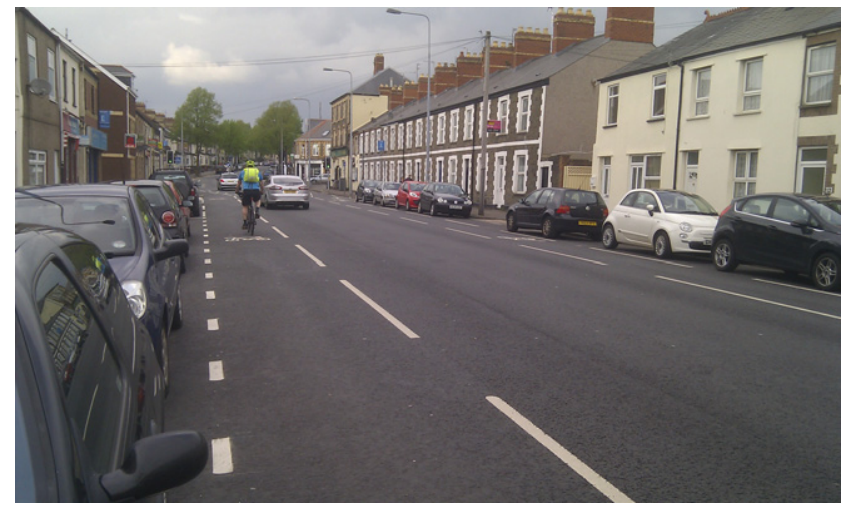

Figure 2. Passing distances are important in relation to cyclist comfort (photo credit: John Parkin)

narrowings with AVs without the facility to use eye contact as part of negotiating the manoeuvre?

Collisions for cyclists are more frequent at junctions than along links, with $63 \%$ of police-recorded collisions in the United Kingdom between 2005 and 2007 occurring at junctions (Knowles et al., 2009). In around 50\% of the reported collisions at junctions, the cyclist is going straight ahead (PJAL, 2016). RQ: How accurate are AVs in detecting cyclists who are making straight on manoeuvres at junctions across side roads either within the carriageway or on adjacent cycle tracks and what is the ability of the AV to come to a correct decision about its behaviour in relation to the cyclist or cyclists?

Walker (2005) found that arm signals worked relatively well to inform drivers of the cyclist's intentions at junctions and were easier to perceive than informal signals. He also found that arm signals often slowed down decision-making processes, leading to a lower probability of their stopping in time when the cyclist was at risk. The same was true for informal signals in which there was eye contact between the cyclist and the driver. These effects may come about because both arm signals and eye contact are communicative acts and therefore produce extra stages of involuntary cognitive processing in the drivers, thereby slowing their reactions. $R Q$ : What is the extent to which $A V$ s are able to decipher cyclists arm signals accurately at junctions?

\subsection{Interactions between AVs and pedestrians}

The current UK Highway Code (DfT, 2016) advises pedestrians to yield to motorists in most circumstances and to abide by the traffic management measures provided for them. Underlying these rules is the notion that interactions between users of the transport network are predominantly controlled through traffic engineering and regulation, rather than through on-road negotiations between users. RQ: how ought the Highway Code to be adapted to provide guidance to pedestrians 
(and other road users) on how to negotiate right of way with $A V s$ ? This is linked in some ways with the 'trolley problem' discussed above. RQ: How does the general population think AVs ought to be programmed to take action in the event of unavoidable collisions involving pedestrians?

In a similar manner as for cyclists discussed above, there are issues about how AVs will detect and respond to pedestrians' signals and gestures. RQ: How will AV sensing be able to detect and react to signals that pedestrians are gesturing and how will these be interpreted by the AV in its decision making?

Pedestrians have different capabilities based on age and this is often manifest in walking speed (Cresswell et al., 1978; Griffiths et al., 1984; Wilson and Grayson, 1980). RQ: How will $A V s$ be able to detect different types of pedestrian (e.g. children and older people) in the environment and be primed to respond to potential crossing interactions accordingly? $R Q$ : Will severance for pedestrians created by streams of motor traffic be increased or reduced by the presence of $A V s$ ?

Interaction between pedestrians and $\mathrm{AVs}$ will occur mainly at carriageway crossings and hence an important interaction issue relates to gap acceptance (Brewer et al., 2006). RQ: Will pedestrians' intention to cross change as an AV (of varying levels of overtness) approaches and will this vary according to demographic (age, gender) or situational characteristics (traffic volume, road type, prior experience of $A V s)$ ? RQ: Should $A V s$ signal that they have 'seen' waiting pedestrians and intend to give way, and if so, how should they do that?

In a study of zebra crossings, Varhelyi (1998) found that drivers give way less than half of the time, but they are more willing to stop if they are already travelling slowly. $R Q$ : Are AVs programmable to effectively and automatically adapt their speed within zebra crossing 'decision zones' regardless of whether pedestrians are present? RQ: What is the extent to which AVs are programmable to effectively and consistently respond to different types of crossing treatment?

As Rule 8 of the UK Highway Code states, pedestrians have right of way across a side road if they have already begun to cross. This poses potentially interesting dilemmas depending on the relative speed of approach of the pedestrian and traffic within the carriageway. RQ: How good are AVs at detecting pedestrians approaching and crossing side roads and are they able to respond accordingly? RQ: How do pedestrians react to an $A V$ (of varying levels of overtness) when deciding whether to start to cross a side road?

Pedestrian behaviour at signal controlled crossings has been studied by various researchers (Davies, 1992; Parkin and Wilson, 2010). RQ: What is the extent to which an $A V$ will be able to detect non-compliance with signal controlled crossings by pedestrians who have become frustrated with the delay imposed on them by the signalisation of crossings? RQ: How will AVs respond to non-compliance (i.e. would an $A V$ be required to defer to a pedestrian in its path in all situations when safe to do so, even on higher-speed roads)?

Shared space has been extensively studied in relation to vehicle-with-pedestrian conflicts (Kaparias et al., 2013; Moody and Melia, 2014). RQ: How do AVs affect perceptions of shared space among pedestrians? RQ: Will pedestrians feel more or less able to gain priority over $A V S$ (compared to driven vehicles) in Shared Spaces?

\subsection{Final general themes}

$\mathrm{AV}$, as they develop further, will begin to learn how to interact based on the recorded experiences the vehicles have had, and this machine learning will in some ways and to some extent parallel the way that humans have learned to interact on roads. This combination of machine and human learning and adaptation will co-evolve and the result will be revised 'cultures' and 'practices' in both the human and the machine. RQ: How will the evolution of machine learning and related human learning take place while maintaining safe interactions between vehicles and cyclists? RQ: What roles will cyclists and pedestrians have in a driverless society and how will the presence of driverless vehicles change pedestrians' and cyclists' facility preferences and behaviour?

The motor car changed social norms around how roads and streets are used and how urban areas are planned (Buchanan, 1963). Few would argue that mistakes have not been made in how engineers and planners and policy makers have responded to the technology of the motor car (Shaw and Docherty, 2013), but of course there are many who will emphasise achievements in highway and traffic engineering (Johnson, 2008).

De minimis, design may passively accommodate $\mathrm{AV}$ s and risk negative consequences such as more motorised traffic with commensurate reductions in priority for non-motorised road users. Alternatively, there is the potential for us to design systems in which $\mathrm{AVs}$ have a fundamentally different relationship with remaining non-autonomous traffic (be that human-driven motor traffic, cycle users or pedestrians). Transport engineering and planning professions will shape those future relationships and indeed the shape of the urban public realm. RQ: What will the main sources of influence be in shaping the philosophy of transport and urban planning and management in response to $A V s$ ?

\section{Summary and next steps}

On the one hand, there are significant uncertainties and potentially long timelines to the introduction of level 5 autonomy, 
Table 1. Research questions by theme

\begin{tabular}{|c|c|}
\hline Thematic area & Research questions \\
\hline \multirow{5}{*}{$\begin{array}{l}\text { AV interactions } \\
\text { with motor } \\
\text { vehicles }\end{array}$} & $\begin{array}{l}\text { MV 1. As a result of their greater predictability, will the presence of AVs introduce a degree of additional control into } \\
\text { the vehicle mix, resulting in fewer errors by drivers? }\end{array}$ \\
\hline & $\begin{array}{l}\text { MV 2. How might an } A V \text { manage a situation in which another driver is being deliberately antagonistic, and driving in a } \\
\text { manner with the intention to harm the } A V \text { and/or its occupants? }\end{array}$ \\
\hline & $\begin{array}{l}\text { MV 3. What decision-making behaviour may be required of an AV to deal with aggressive behaviour of a human driver } \\
\text { in following a vehicle? }\end{array}$ \\
\hline & $\begin{array}{l}\text { MV 4. Do approaching AVs engender a different gap acceptance behaviour among other road users (including cyclists } \\
\text { and pedestrians) at junctions and does this vary depending on how obvious it is that a vehicle is an AV? }\end{array}$ \\
\hline & MV 5. How will AVs behave in shared space? \\
\hline \multirow[t]{11}{*}{$\begin{array}{l}\text { AV interactions } \\
\text { with cycles }\end{array}$} & $\begin{array}{l}\text { C 1. Will AVs assist, in the generality, in changing the perceptions of hazard posed by motorised traffic to cycle users? RQ: } \\
\text { How does the presence of AVs with differing levels of automation affect interactions and decisions made by cyclists? }\end{array}$ \\
\hline & $\begin{array}{l}\text { C 2. To what extent would AVs be able to detect a cyclist in the road ahead when light and weather conditions are } \\
\text { adverse? }\end{array}$ \\
\hline & C 3. Can an AV remain 'passively' safe by preventing passenger egress when it is not safe to do so? \\
\hline & C 4. Will cyclists allocate attention differently and behave differently around AVs in queueing traffic? \\
\hline & $\begin{array}{l}\text { C 5. What legislative changes might be particularly appropriate or helpful in the context of managing AV interactions } \\
\text { with non-motorised road users? }\end{array}$ \\
\hline & C 6. How may perceived risks be altered for cycle users by the presence of AVs in the vehicle stream? \\
\hline & $\begin{array}{l}\text { C 7. For different speeds, what is an appropriate distance to be provided by an AV when overtaking a cyclist in order } \\
\text { to provide a minimum level of comfort for the cyclist? }\end{array}$ \\
\hline & $\begin{array}{l}\text { C } 8 \text {. Are AVs able to overtake cyclists both with and without centre line markings with no difference in the impact on } \\
\text { cycle users' perceptions of safety? }\end{array}$ \\
\hline & $\begin{array}{l}\text { C 9. How will cycle users negotiate road narrowings with AVs without the facility to use eye contact as part of } \\
\text { negotiating the manoeuvre? }\end{array}$ \\
\hline & $\begin{array}{l}\text { C 10. How accurate are AVs in detecting cyclists who are making straight on manoeuvres at junctions across side roads } \\
\text { either within the carriageway or on adjacent cycle tracks and what is the ability of the AV to come to a correct } \\
\text { decision about its behaviour in relation to the cyclist or cyclists? }\end{array}$ \\
\hline & C 11. What is the extent to which AVs are able to decipher cyclists arm signals accurately at junctions? \\
\hline \multirow[t]{14}{*}{$\begin{array}{l}\text { AV Interactions } \\
\text { with pedestrians }\end{array}$} & $\begin{array}{l}\text { P 1. How ought the Highway Code to be adapted to provide guidance to pedestrians (and other road users) on how } \\
\text { to negotiate right of way with AVs? }\end{array}$ \\
\hline & $\begin{array}{l}\text { P 2. How will } A V \text { sensing be able to detect and react to signals that pedestrians are gesturing and how will these be } \\
\text { interpreted by the } A V \text { in its decision making? }\end{array}$ \\
\hline & $\begin{array}{l}\text { P 3. How will AVs be able to detect different types of pedestrian (e.g. children and older people) in the environment } \\
\text { and be primed to respond to potential crossing interactions accordingly? }\end{array}$ \\
\hline & P 4. Will severance for pedestrians created by streams of motor traffic be increased or reduced by the presence of AVs? \\
\hline & $\begin{array}{l}\text { P 5. Will pedestrians' intention to cross change as an AV (of varying levels of overtness) approaches and will this vary } \\
\text { according to demographic (age, gender) or situational characteristics (traffic volume, road type, prior experience of AVs)? }\end{array}$ \\
\hline & $\begin{array}{l}\text { P 6. Should AVs signal that they have 'seen' waiting pedestrians and intend to give way, and if so, how should they } \\
\text { do that? }\end{array}$ \\
\hline & $\begin{array}{l}\text { P 7. Are AVs programmable to effectively and automatically adapt their speed within zebra crossing 'decision zones' } \\
\text { regardless of whether pedestrians are present? }\end{array}$ \\
\hline & $\begin{array}{l}\text { P 8. What is the extent to which AVs are programmable to effectively and consistently respond to different types of } \\
\text { crossing treatment? }\end{array}$ \\
\hline & $\begin{array}{l}\text { P 9. How good are AVs at detecting pedestrians approaching and crossing side roads and are they able to respond } \\
\text { accordingly? }\end{array}$ \\
\hline & P 10. How do pedestrians react to an AV (of varying levels of overtness) when deciding whether to start to cross a side road? \\
\hline & $\begin{array}{l}\text { P 11. What is the extent to which an AV will be able to detect non-compliance with signal controlled crossings by } \\
\text { pedestrians who have become frustrated with the delay imposed on them by the signalisation of crossings? }\end{array}$ \\
\hline & $\begin{array}{l}\text { How will AVs respond to non-compliance (i.e. would an AV be required to defer to a pedestrian in its path in all } \\
\text { situations when safe to do so, even on higher-speed roads)? }\end{array}$ \\
\hline & P 13. How do AVs affect perceptions of shared space among pedestrians? \\
\hline & P 14. Will pedestrians feel more or less able to gain priority over AVs (compared to driven vehicles) in shared spaces? \\
\hline \multirow[t]{3}{*}{ General themes } & $\begin{array}{l}\text { G 1. How will the evolution of machine learning and related human learning take place while maintaining safe } \\
\text { interactions between vehicles and cyclists? }\end{array}$ \\
\hline & $\begin{array}{l}\text { G 2. What roles will cyclists and pedestrians have in a driverless society and how will the presence of driverless vehicles } \\
\text { change pedestrians' and cyclists' facility preferences and behaviour? }\end{array}$ \\
\hline & $\begin{array}{l}\text { G 3. What will the main sources of influence be in shaping the philosophy of transport and urban planning and } \\
\text { management in response to AVs? }\end{array}$ \\
\hline
\end{tabular}


particularly, on urban roads. On the other, this is a rapidly developing field, with significant claims being made in some quarters. Table 1 summarises the research questions by thematic areas that have emerged from the literature review and answers to these will help to reduce some of these uncertainties.

It is clear that there are many questions to be addressed in relation to the interaction of technology with other road users as humans. An important question for the policy and research community is now concerned with how these questions might be prioritised. There are a number of domains that $\mathrm{AVs}$ will influence, including attitudes and behaviours in relation to transport generally and mode and route choice in particular and, of course, safety. On the one hand, technology stakeholders in this field of inquiry might be more principally concerned with developing minimum viable products to place in the market as soon as possible. On the other, policy makers have a key role in regulating not only the ultimate environments in which $\mathrm{AVs}$ might operate, but also the processes and procedures as the future unfolds. Based on the nature and extent of the questions, it could be argued, certainly in the context of urban roads, that the more pressing and safety critical issues concern interactions with cycle users and pedestrians. This is partly resulting from the rather different and more heterogeneous forms of interaction that exist between these user groups and motor vehicle drivers.

The introduction of new vehicle technology will have significant implications for the way that the design and management of urban road infrastructure is approached. The Venturer project is undertaking three sets of trials using the Wildcat vehicle. The first set observed the hand-over of control from the AV back to the human driver. The second set tested the trust of $\mathrm{AV}$ passenger in both the Wildcat and the Venturer simulator to being driven with other motor vehicles present. The third set of trials explores trust where there are pedestrian and cyclists present. The literature review that has been summarised in this paper, together with the resulting research questions that emerge, has been forming one of the inputs into the development of the design of the trials.

\section{REFERENCES}

AAA (American Automobile Association) (2009) Aggressive Driving: Research Update April, 2009. American Automobile Association, Washington, DC, USA. See http://www.aaafoundation.org/sites/ default/files/AggressiveDrivingResearchUpdate2009.pdf (accessed 09/02/2016).

Adams J (2015) Self-Driving Cars and the Child-Ball Problem: Why Autonomous Vehicles are not the Answer. See http://essays. centreforlondon.org/issues/technology/self-driving-cars-and-thechild-ball-problem-why-autonomous-vehicles-are-not-the-answer/ (accessed 25/10/2017).

Aldred R (2016) Cycling near misses: their frequency, impact, and prevention. Transportation Research Part A: Policy and Practice 90: 69-83, https://doi.org/10.1016/j.tra.2016.04.016.
Asbridge M, Smart RG and Mann RE (2003) The 'homogamy' of road rage: understanding the relationship between victimization and offending among aggressive and violent motorists. Violence and Victims 18(5): 517-531.

Audi (2015) Audi Piloted Driving. Audi, Ostfildern-Scharnhausen, Germany. See http://www.audi.com/content/com/brand/en/ vorsprung_durch_technik/content/2014/10/piloted-driving.html (accessed 12/02/2016).

Bonnefon JF, Shariff A and Rahwan I (2015) Autonomous vehicles need experimental ethics: are we ready for utilitarian cars? arXiv preprint arXiv:1510.03346. See https://pdfs.semanticscholar.org/ 13d4/56d4c53d7b03b90ba59845a8f61b23b9f6e8.pdf (accessed 06/11/2017).

Bonnefon JF, Shariff A and Rahwan I (2016) The social dilemma of autonomous vehicles. Science 352(6293): 1573-1576.

Brewer M, Fitzpatrick K, Whitacre J and Lord D (2006) Exploration of pedestrian gap-acceptance behavior at selected locations. Transportation Research Record 1982: 132-140.

Buchanan C (1963) Traffic in Towns. Report of the Steering Group. HMSO, London, UK.

Cresswell C, Griffiths JD and Hunt JG (1978) Site evaluation of a pelican crossing simulation model. Traffic Engineering and Control 19(12): 546-549.

Dąbrowski P (2014) Psychological aspects of aggressive behavior in traffic of drivers - parents transporting children. Studia Gdańskie. Wizje i Rzeczywistość 11: 43-59.

Davies HEH (1992) The Puffin Pedestrian Crossing: Experience with the First Experimental Sites. Transport Research Laboratory, Crowthorne, UK, Research Report 364.

DfT (Department for Transport) (2007) Manual for Streets. DfT, London, UK. See http://www.communities.gov.uk/publications/ planningandbuilding/manualforstreets (accessed 25/10/2017).

DfT (2015a) Contributory Factors to Reported Road Accidents 2014 (RAS50). Table RAS50002. DfT, London, UK. See http://www. gov.uk/government/statistical-data-sets/ras50-contributoryfactors\#table-ras50001 (accessed 05/02/2016).

Dft (2015b) The Pathway to Driverless Cars: A Code of Practice for Testing. DfT, London, UK.

DfT (2016) The Highway Code. DfT, London, UK. See http://www.gov. uk/guidance/the-highway-code (accessed 21/02/2016).

Dill J and McNeil N (2013) Four types of cyclists? Examination of typology for better understanding of bicycling behavior and potential. Transportation Research Record 2387: 129-138.

Foot P (1967) The Problem of Abortion and the Doctrine of the Double Effect in Virtues and Vices. Oxford: Basil Blackwell, 1978, originally appeared in the Oxford Review, Number 5, 1967.

Forbes (2014) An Update on the Baidu-BMW Driver-Less Car Deal as Further Details Emerge. Forbes, Jersey City, NJ, USA. See http://www.forbes.com/sites/greatspeculations/2014/10/03/anupdate-on-the-baidu-bmw-driver-less-car-deal-as-further-detailsemerge/ (accessed 12/02/2016).

Fraser SDS and Lock K (2010) Cycling for transport and public health: a systematic review of the effect of the environment on cycling. European Journal of Public Health 21(6): 738-743.

Frings D, Parkin J and Ridley AM (2014) The effects of cycle lanes, vehicle to kerb distance and vehicle type on cyclists' attention allocation during junction negotiation. Accident Analysis and Prevention 72: 411-421, https://doi.org/10.1016/j.aap.2014.07.034.

Garrard J, Handy S and Dill J (2012) Women and cycling. In City Cycling (Pucher J and Buehler R (eds)). MIT Press, Cambridge, MA, USA, pp. 211-234.

Goldhill (2015) Should Driverless Cars Kill their Own Passengers to Save a Pedestrian. Goldhill, New York, NY, USA. 
See http://qz.com/536738/should-driverless-cars-kill-their-ownpassengers-to-save-a-pedestrian/ (accessed 21/02/2016).

Gray LN and Tallman I (1984) A satisfaction balance model of decision making and choice behavior. Social PsychoIogy Quarterly 47(2): $146-159$.

Griffiths JD, Hunt JG and Marlow M (1984) Delays at pedestrian crossings: 1 . Site observations and the interpretation of data. Traffic Engineering and Control 25(7-8): 365-371.

Gstalter H and Fastenmeier W (2010) Reliability of drivers in urban intersections. Accident Analysis and Prevention 42(1): 225-234.

Hamilton-Baillie B and Jones P (2005) Improving traffic behaviour and safety through urban design. Proceedings of the Institution of Civil Engineers - Civil Engineering 158(5): 39-47.

Hardy B and Fenner RA (2015) Towards the sustainability of road transport through the introduction of $\mathrm{AV}$ technology. Proceedings of the Institution of Civil Engineers: Engineering Sustainability 168(ES5): 192-203.

Harkey DL, Reinfurt DW and Knuiman M (1998) Development of the bicycle compatibility index. Transportation Research Record 1636: 13-20.

Harrell WA and Spaulding LM (2001) Social psychological models of choice behavior and drivers' left turns. The Journal of Social Psychology 141(6): 714-722.

HE (Highways England) (2016) Smart Motorways Programme. Highways England, Birmingham, UK. See http://www. highways.gov.uk/smart-motorways-programme/ (accessed 18/11/2016)

Hennessy DA (2011) Social, personality, and affective constructs in driving. In Handbook of Traffic Psychology (Porter BE (ed.)). Academic Press/Elsevier, Cambridge, MA, USA, pp. 149-163.

Johnson WM (2008) The Motorway Achievement: Motorway Management in the United Kingdom, the First Fifty Years. Phillimore for the Motorway Archive Trust: Bognor Regis, Wokingham, UK.

Joint M (1997) Road rage. In American Automobile Association Foundation for Traffic Safety. Aggressive Driving: Three Studies. American Automobile Association (AAA), Washington, DC, USA. See http://www.aaafoundation. org/sites/default/files/agdr3study.pdf (accessed 09/02/2016).

Kaparias I, Bell M, Dong W et al. (2013) Analysis of pedestrian-vehicle traffic conflicts in street designs with elements of shared space. Transportation Research Record 2393: 21-30.

Knowles J, Adams S, Cuerden R et al. (2009) Collisions Involving Pedal Cyclists on Britain's Roads: Establishing the Causes. Transport Research Laboratory, Crowthorne, UK, PPR445.

Lemonnier S, Brémond R and Baccino T (2015) Gaze behavior when approaching an intersection: dwell time distribution and comparison with a quantitative prediction. Transportation Research Part $F \mathbf{3 5}$ : 60-74, http://dx.doi.org/10.1016/j.trf.2015.10.015.

Lewis D (2015) Google's Driverless Car Got Confused by A Cyclist. The Smithsonian, Washington, DC, USA. See http://www. smithsonianmag.com/smart-news/googles-driverless-car-gotconfused-cyclist-180956465/?no-ist (accessed 12/02/2016).

Miles DE and Johnson GL (2003) Aggressive driving behaviors: are there psychological and attitudinal predictors? Transportation Research Part F: Traffic Psychology \& Behaviour 6(2): 147-161.

Moody S and Melia S (2014) Shared space - research, policy and problems. Proceedings of the Institution of Civil Engineers Transport 167(6): 384-392.

Parkin J and Meyers C (2010) The effect of cycle lanes on the proximity between motor traffic and cycle traffic. Accident Analysis and Prevention 42(1): 159-165.
Parkin J and Wilson R (2010) Adequacy of operation and delay to pedestrians and vehicles under 'Pelican' and 'Puffin' type control at signal controlled crossings. Proceedings of the 12th World Conference on Transport Research, Lisbon, Portugal.

Parkin J, Wardman M and Page M (2007) Models of perceived cycling risk and route acceptability. Accident Analysis and Prevention 39(2): 364-371.

Parkin J, Clark B, Clayton W, Ricci M and Parkhurst G (2016) Understanding Interactions between Autonomous Vehicles and Other Road Users: A Literature Review. University of the West of England, Bristol, UK, Project Report. See http:// eprints.uwe.ac.uk/29153 (accessed 18/12/2016).

PJAL (Phil Jones Associates Ltd) (2016) Cycling Priority at Junctions. British Cycling, Manchester, UK.

Postauto (2016) Smart Shuttle Project. Postauto, Bern, Switzerland. See http://www.postauto.ch/en/smartshuttle-projekt (accessed 18/11/2016).

Risser R (1985) Behavior in traffic conflict situations. Accident Analysis and Prevention 17(2): 179-197.

Robinson BJ and Scoons J (2013) Cycle Regulations Review Final Report. Transport Research Laboratory (TRL), London, UK.

RoSPA (Royal Society for the Prevention of Accidents) (2011) Inappropriate Speed. Royal Society for the Prevention of Accidents, Birmingham, UK. See http://www.rospa.com/roadsafety/advice/drivers/speed/inappropriate/ (accessed 09/02/2016).

Sabey BE and Taylor H (1980) The Known Risks We Run: The Highway. Transport and Road Research Laboratory, Crowthorne, UK, Supplementary Report 567.

SAE (Society of Automotive Engineers) International (2014) Automated Driving Levels of Driving Automation are Defined in New SAE International Standard J3016. Society of Automotive Engineers International, Warrendale, PA, USA. See http://www.sae. org/misc/pdfs/automated_driving.pdf (accessed 18/11/2016).

Sanders S (2002) Aggression and violence associated with motor vehicle use. In Bullying, Intimidation, Abuse and Assault on the RoadSelected Australasian Research and Comment on 'Road Rage' and Aggressive driving (Faulks IJ (ed.)), report no. 18/52, pp. 315-363.

Schafer K (2015) The Road Rage and Aggressive Driving Dichotomy: Personality and Attribution Factors in Driver Aggression. HIM 1990-2015. Paper 611.

Shackel SC and Parkin J (2014) Influence of road markings, lane widths and driver behaviour on proximity and speed of vehicles overtaking cyclists. Accident Analysis and Prevention 73: 100-108, https://doi.org/10.1016/j.aap.2014.08.015.

Shaw J and Docherty I (2013) The Transport Debate. Policy Press, Bristol, UK.

Simonite T (2013) Data Shows Google's Robot Cars are Smoother, Safer Drivers than You or I. MIT Technology Review, Cambridge, MA, USA. See http://www.technologyreview.com/news/520746/datashows-googles-robot-cars-are-smoother-safer-drivers-than-you-or-i/ (accessed 12/02/2016).

Skinner R and Bidwell N (2016) Making Better Places: Autonomous Vehicles and Future Opportunities. WSPPB and Farrells, London, UK. See http://www.wsp-pb.com/Globaln/UK/WSPPB-FarrellsAV-whitepaper.pdf (accessed 28/11/2016).

Stewart K and McHale A (2014) Cycle lanes: their effect on driver passing distances in urban areas. Transport 29(3): 307-316.

Svensson A and Hydén C (2006) Estimating the severity of safety related behaviour. Accident Analysis and Prevention 38(2): $379-385$.

Tesla (2015) Model S Software Version 7.0. Tesla Model S Press Release, Palo Alto, CA, USA. See http://www.teslamotors. com/presskit/autopilot (accessed 12/02/2016). 
Thrift N (2004) Driving in the city. Theory, Culture and Society 21(4/5): $41-59$.

ULTraglobalPRT (2016) Heathrow Pod. UltraglobalPRT, Bristol, UK. See http://www.ultraglobalprt.com/wp-content/uploads/2011/10/ Ultra_SelfTour2.pdf (accessed 18/11/2016).

Varhelyi A (1998) Drivers' speed behaviour at a zebra crossing: a case study. Accident Analysis \& Prevention 30(6): 731-743.

VCG (Volvo Car Group) (2014) Volvo Car Group's First Self-Driving Autopilot Cars Test on Public Roads Around Gothenburg. VCG, Göteborg, Sweden. See http://www.media.volvocars.com/global/en$\mathrm{gb} / \mathrm{media} /$ pressreleases/145619/volvo-car-groups-first-self-drivingautopilot-cars-test-on-public-roads-around-gothenburg (accessed $12 / 02 / 2016)$.

VCG (2015) Volvo Cars Presents a Unique System Solution for Integrating Self-Driving Cars into Real Traffic. VCG, Göteborg, Sweden. See http://www.media.volvocars.com/global/en$\mathrm{gb} / \mathrm{media} /$ pressreleases/158276/volvo-cars-presents-a-uniquesystem-solution-for-integrating-self-driving-cars-into-real-traffic (accessed 12/02/2016).

Venturer Consortium (2017) http://www.venturer-cars.com (accessed $31 / 10 / 2017)$.

Walker I (2005) Signals are informative but slow down responses when drivers meet bicyclists at road junctions. Accident Analysis and Prevention 37(6): 1074-1085.
Walker I (2007) Drivers overtaking bicyclists: objective data on the effects of riding position, helmet use, vehicle type and apparent gender. Accident Analysis and Prevention 39(2): 417-425.

Wardman M, Page M, Tight M and Siu YL (2000) Cycling and Urban Commuting: Results of Behavioural Mode and Route Choice Models. Institute for Transport Studies, University of Leeds, Leeds, UK, Working Paper 548.

Wickens CM, Wiesenthal DL, Flora DB and Flett GL (2011) Understanding driver anger and aggression: attributional theory in the driving environment. Experimental Psychology: Applied 17(4): 354 (Cited in Schafer, 2015).

Wilde GJS (1976) Social interaction patterns in driver behavior: an introductory review. Human Factors 18(5): 477-492.

Wilson DG and Grayson GB (1980) Age-Related Differences in the Road Crossing Behaviour of Adult Pedestrians. Transport Research Laboratory, Berkshire, UK, Report No. LR 933.

Winters M, Davidson G, Kao D and Teschke K (2011) Motivators and deterrents of bicycling: comparing influences on decisions to ride. Transportation 38(1): 153-168.

Wood JM, Lacherez PF, Marszalek RP and King MJ (2009) Drivers' and cyclists' experiences of sharing the road: incidents, attitudes and perceptions of visibility. Accident Analysis \& Prevention 41(4): $772-776$.

\section{How can you contribute?}

To discuss this paper, please email up to 500 words to the editor at journals@ice.org.uk. Your contribution will be forwarded to the author(s) for a reply and, if considered appropriate by the editorial board, it will be published as discussion in a future issue of the journal.

Proceedings journals rely entirely on contributions from the civil engineering profession (and allied disciplines).

Information about how to submit your paper online is available at www.icevirtuallibrary.com/page/authors, where you will also find detailed author guidelines. 